\title{
Ectopic Expression of the Rice Lumazine Synthase Gene Contributes to Defense Responses in Transgenic Tobacco
}

\author{
Tingquan Wu, An Guo, Yanying Zhao, Xiaomeng Wang, Ying Wang, Dan Zhao, \\ Xiaojie Li, Haiying Ren, and Hansong Dong
}

Plant Growth and Defense Signaling Laboratory, Group of Key Laboratory of Monitoring and Management of Crop Pathogens and Insect Pests, Ministry of Agriculture, P. R. China, Nanjing Agricultural University, Nanjing 210095, China.

Current address of H. Ren: The Institute of Plant Protection and Microbiology, Zhejiang Academy of Agricultural Sciences, Hangzhou 310021, China.

Accepted for publication 3 January 2010.

\begin{abstract}
Wu, T., Guo, A., Zhao, Y., Wang, X., Wang, Y., Zhao, D., Li, X., Ren, H., and Dong, H. 2010. Ectopic expression of the rice lumazine synthase gene contributes to defense responses in transgenic tobacco. Phytopathology 100:573-581.

Lumazine synthase (LS) catalyzes the penultimate reaction in the multistep riboflavin biosynthesis pathway, which is involved in plant defenses. Plant defenses are often subject to synergistic effects of jasmonic acid and ethylene whereas LS is a regulator of jasmonic acid signal transduction. However, little is known about whether the enzyme contributes to defense responses. To study the role of LS in plant pathogen defenses, we generated transgenic tobacco expressing the rice

identity with its homologues in higher plants and less homology to microbial orthologues. The OsLS protein localized to chloroplasts in three $O s L S$-expressing transgenic tobacco (LSETT) lines characterized as enhanced in growth and defense. Compared with control plants, LSETT had higher content of both riboflavin and the cofactors flavin mononucleotide and flavin adenine dinucleotide. In LSETT, jasmonic acid and ethylene were elevated, the expression of defense-related genes was induced, levels of resistance to pathogens were enhanced, and resistance was effective to viral, bacterial, and oomycete pathogens. Extents of $O s L S$ expression correlated with increases in flavin, jasmonic acid, and ethylene content, and correlated with increases in resistance levels, suggesting a role for $O s L S$ in defense responses.
\end{abstract} (Oryza sativa) LS gene, OsLS. OsLS was cloned and found to have strong
Flavins have three major forms: riboflavin (RIB), or vitamin $\mathrm{B}_{2}$; flavin mononucleotide (FMN); and flavin adenine dinucleotide (FAD) $(28,31)$. RIB is the precursor of FMN and FAD, which are essential cofactors for several metabolic enzymes in critical cellular processes $(18,36)$, such as the citric acid cycle in all organisms and mitochondrial electron transport in plants (18). RIB biosynthesis occurs through a nine-step pathway (Fig. 1) that is similar in all organisms $(18,32)$. At the penultimate step, 6,7dimethyl-8-ribityllumazine (lumazine) synthase (LS) catalyzes the condensation of 5-amino-6-ribitylamino-2,4 $(1 \mathrm{H}, 3 \mathrm{H})$-pyrimidinedione with 3,4-dihydroxy-2-butanone 4-phosphate to produce lumazine $(13,18)$. The final step in RIB biosynthesis is the dismutation of lumazine, catalyzed by RIB synthase (13). Subsequently, RIB is converted to FMN and FMN is converted to FAD required for multiple cellular processes $(13,17,18$, 28,31,32,34,36).

In plants, RIB synthesis and the flavin conversion reactions are predicted to occur mainly in chloroplasts (34). Flavins are subsequently transported by subcellular trafficking and function in processes such as mitochondrial electron transport $(17,18)$. Thus, chloroplasts can exert control over the electron transport chain remotely, and monitor the cellular redox status $(12,24)$. The cellular redox status has an important role in plant defense

Corresponding author: H. Dong; E-mail address: hsdong@ @jau.edu.cn

* The $\boldsymbol{e}$-Xtra logo stands for "electronic extra" and indicates that the online version contains four additional figures not available in the print version.

doi:10.1094/PHYTO-100-6-0573

(C) 2010 The American Phytopathological Society responses regulated by the plant hormones jasmonic acid (JA) and ethylene, which are synergistic in regulation of defense responses $(10,44,46)$. JA signal transduction recruits the regulator COS1, a protein that has been identified as LS in Arabidopsis thaliana) (44). Therefore, the RIB biosynthesis pathway and flavin conversions are thought to affect plant defenses by influencing JA/ ethylene signal transduction.

We have investigated plant defenses that are induced by the extrinsic application of RIB $(10,46)$, inspired by the important role of RIB as an indispensable vitamin for animals and a therapeutic treatment for animal and human diseases $(8,28,43)$. Although plants can synthesize RIB, the levels vary widely in different organs and during different stages of development $(27,31,35$, $47)$, indicating that changes in RIB levels may have physiological effects $(23,37,41)$. Foliar application of RIB enhances growth (27) and controls diseases (41), consistent with studies that show that RIB triggers distinct signaling processes $(8,27,37,44,46)$, such as the ethylene signal transduction pathway (27) and the systemic acquired resistance pathway $(10,46)$. This pathway is mediated by salicylic acid $(7,33)$ and regulated by the ankyrincontaining protein NPR1 $(3,4,11)$. Interestingly, NPR1 but not salicylic acid is required for RIB-induced pathogen resistance in plants (10). These findings suggest that the extrinsic use of RIB affects plant resistance via interactions with known defensive pathways.

The extrinsic application of RIB to plants might not duplicate the functions of intrinsically generated RIB. In this study, we cloned the Oryza sativa LS-encoding gene OsLS, the fourth $L S$ gene so far identified in plants. Then, we used $O s L S$ to manipulate the intrinsic RIB content in transgenic tobacco. Transgenic plants were investigated to determine whether LS plays a role in defense responses. 


\section{MATERIALS AND METHODS}

Cloning of OsLS. Specific primers 5'-GCGGATCCAT GGCGGCGGCTGC-3' and 5'-GCGTCGACTCAGGCCAGGTG ATGCT-3' were synthesized according to the $O s L S$ sequence OSJNBa0067K08.20, as annotated by the International Rice Genome Sequencing Project (IRGSP; http://rgp.dna.affrc.go.jp/ IRGSP/index.html). Italics indicate BamHI and SalI restriction sites. Polymerase chain reaction (PCR) used the Tripure Isolution Reagent Kit (Roche Diagnostics [Shanghai] Trading Co., Ltd., Shanghai, China) and genomic DNA isolated from Zhonghua11, a japonica rice cultivar planted widely throughout China. PCR products were analyzed by agarose gel electrophoresis and visualized by staining with ethidium bromide $(5,27)$. The PCR product sequence was confirmed (5) to be homologous to OSJNBa0067K08.20, and deposited in the GenBank database under accession no. GQ202237. The gene was cloned into the prokaryotic expression vector pET30a(+) and the plant transformation and expression vector pBI121 (EMD Bioscience Inc., Gibbstown, NJ).

Manipulation of the OsLS protein. Prokaryotic expression was as described previously (5). The cloned $O s L S$ was inserted into pET30a(+) at the SmalI and BamHI restriction sites and fused to a 132-nucleotide linker between a His-tag of six tandem histidines and the $O S L S$ insert. The recombinant vector was transferred into Escherichia coli BL21 cells to produce the His-OsLS fusion protein. BL21 cells transformed with the vector only were used to produce a control, inactive protein preparation, termed empty vector preparation. Protein preparations were purified by nickel chromatography using the HisTrap HP Kit (Amersham Bioscience Inc., Piscataway, NJ). The resin was saturated with $10 \mathrm{ml}$ of imidazole-binding buffer $(10 \mathrm{mM}, \mathrm{pH} 7.4)$, and proteins were loaded and eluted with $10 \mathrm{mM}$ phosphate buffer containing various concentrations of imidazole. Proteins were subjected to tricine sodium dodecyl sulfate polyacrylamide gel electrophoresis (T-SDS-PAGE). Protein sizes were estimated using the empirical formula molecular weight in daltons $=110 \times$ number of amino acid residues. Transit peptide and subcellular localization of OsLS were predicted with the SignalP3.0 Server program (http://www.expasy.ch) and the Targetp V1.1 program (http:// www.cbs.dtu.dk/services/TargetP/), respectively.

Generation of transgenic plants. OSLS was cloned downstream of the Cauliflower mosaic virus $35 \mathrm{~S}$ promoter (35S) in pBI121, creating pBI121::35S::OsLS, which was transferred into Agrobacterium tumefaciens. Recombinant A. tumefaciens cells were used in transformation of tobacco (Nicotiana tabacum L.) cv. Xanthi (NN) (25). Transformation with the bacterial cells containing the empty vector pBI121::35S was performed as a control. Transgenic plants were screened and characterized as described $(25,42)$. Homozygous progenies in the $\mathrm{T} 3$ generation were used in the study. Plants were grown on the selective medium (25) and incubated in an environment-controlled chamber and in the greenhouse. In the greenhouse, seedlings were grown in a pot nursery for 15 days; then, seedlings were trans-

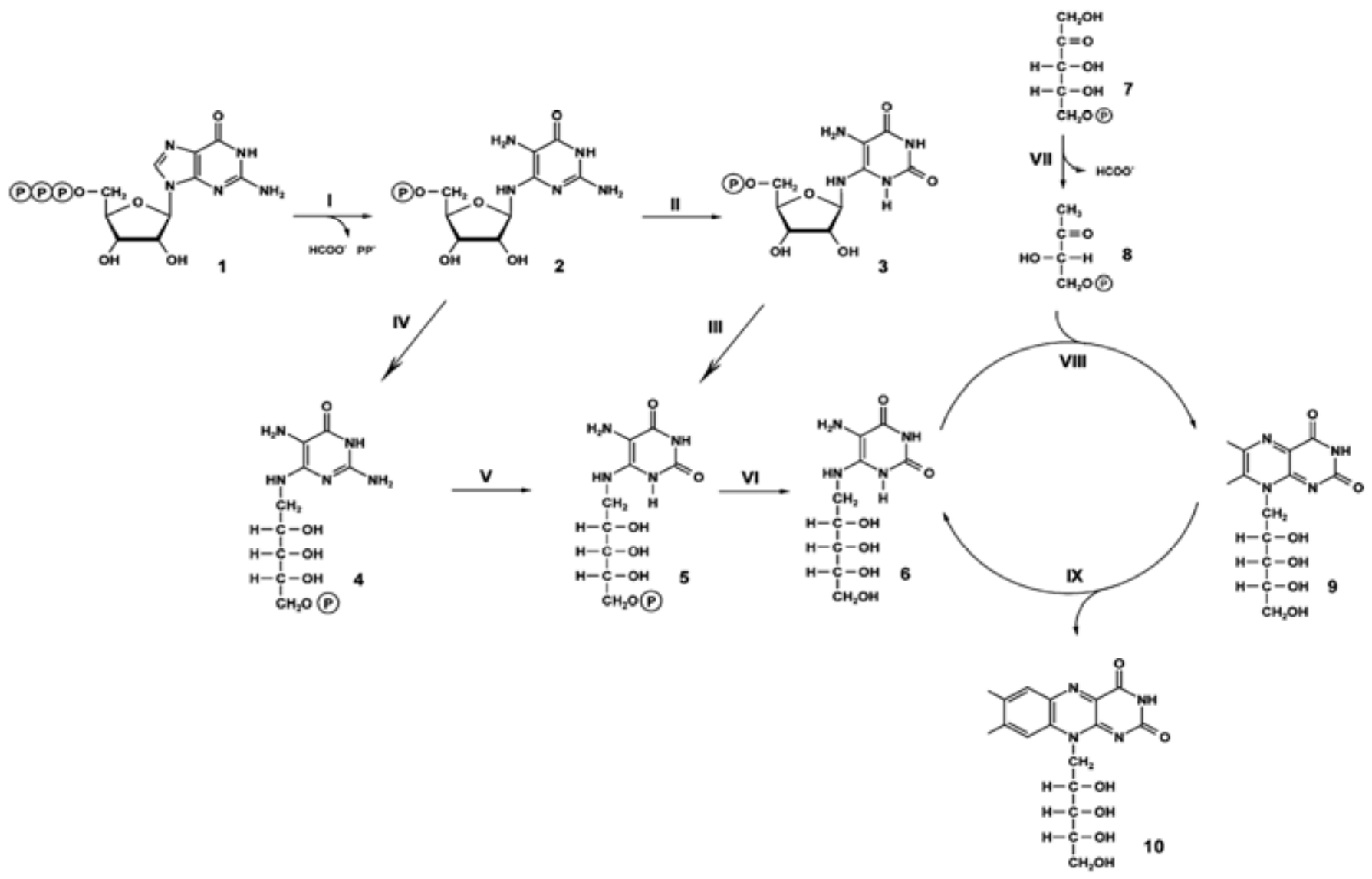

Fig. 1. Biosynthesis of riboflavin and flavocoenzymes. Step I, GTP cyclohydrolase II; step II, 2,5-diamino-6-ribosylamino-4(3H)-pyrimidinone 50-phosphate deaminase; step III, 5-amino-6-ribosylamino-2,4(1H,3H)-pyrimidinedione 50-phosphate reductase; step IV, 2,5-diamino-6-ribosylamino-4(3H)-pyrimidinone 50-phosphate reductase; step V, 2,5-diamino-6-ribitylamino-4(3H)-pyrimidinone 50-phosphate deaminase; step VI, hypothetical phosphatase; step VII, 3,4-dihydroxy-2-butanone 4-phosphate synthase; step VIII, 6,7-dimethyl-8-ribityllumazine synthase; step IX, riboflavin synthase; 1, GTP; 2, 2,5-diamino-6ribosylamino-4(3H)-pyrimidinone 50-phosphate; 3, 5-amino-6-ribosylamino-2,4(1H,3H)-pyrimidinedione 50-phosphate; 4, 2,5-diamino-6-ribitylamino-4(3H)pyrimidinone 50-phosphate; 5 , 5-amino-6-ribitylamino-2,4 $(1 \mathrm{H}, 3 \mathrm{H})$-pyrimidinedione 50 -phosphate; 6 , 5-amino-6-ribitylamino-2,4(1H,3H)-pyrimidinedione; 7 , ribulose 50-phosphate; 8, 3,4-dihydroxy-2-butanone 4-phosphate; 9, 6,7-dimethyl-8-ribityllumazine; 10, riboflavin. The diagram is adopted from a recent review article (13). 
planted into new pots for regular growth. Plant growth was monitored under the different conditions. Chromosomal integration of OsLS was confirmed by PCR and Southern blot analysis (25). For Southern blots, tobacco genomic DNA was digested with BamHI and EcoRI and transferred to a nylon membrane, followed by hybridization to a digoxigenin (DIG)-labeled $O S L S$ probe prepared using the DIG Nucleic Acid Detection Kit (Roche Diagnostics). Western blot analysis detected OsLS in total (20) and chloroplast proteins (30). Blots were incubated with antiOsLS antiserum from immunized rabbits and with horseradish peroxidase-conjugated secondary antibody from the BeyoECL Plus Kit (Beyotime Institute of Biotechnology, Haimen, Jiangsu Province, China).

Immune colloidal gold assay. Plant leaf sections of $1 \mathrm{~mm}^{2}$ were embedded with Lowicryl K4M resin (Cosmo Bio. [Shanghai] Trading Co., Ltd., Shanghai, China) and were polymerized as described (14). Ultrathin sections from the polymerized samples were blocked on nickel grids (16) and probed by immersing the grids in a solution of 10-nm colloidal gold tagged (14) to anti-His or anti-OsLS antiserum. Probed samples were observed by transmission electron microscopy (16).

Flavin measurements. RIB, FMN, and FAD were extracted using extraction buffers A and B (39). Leaf samples were ground on ice with buffer $\mathrm{A}$ and the homogenate was centrifuged at $4{ }^{\circ} \mathrm{C}$, $12,000 \times g$ for $10 \mathrm{~min}$. The supernatant was used to isolate total and free forms of the three flavins. Total flavins were isolated as described (39). To isolate free flavins, $500 \mu \mathrm{l}$ of supernatant was loaded into a Microcon YM-3 (3 kDa NMWL) ultrafiltration spin column (Millipore [Shanghai] Trading Co., Ltd., Shanghai, China), which was centrifuged at $4^{\circ} \mathrm{C}, 14,000 \times g$ for $15 \mathrm{~min}$. The flow-through $(200 \mu \mathrm{l})$ was mixed with buffer $\mathrm{B}(1 \mathrm{ml})$ and centrifuged at $4^{\circ} \mathrm{C}, 12,000 \times g$ for $10 \mathrm{~min}$. The supernatant contained free flavins. Total or free flavins were filtered through $0.22-\mu \mathrm{m}$ blend cellulose ester filters (Millipore [Shanghai] Trading Co., Ltd.) and analyzed by high-performance liquid chromatography. Concentrations of RIB, FMN, and FAD were determined as described (6).

Pathogen inoculation. Wild-type (WT) and transgenic tobacco were grown in the greenhouse. Forty-day-old plants were inoculated with Tobacco mosaic virus (TMV), Pectobacterium carotovorum subsp. carotovorum ((Jones) Bergey et al.), and Phytophthora parasitica var. nicotianae (Tucker). TMV was maintained in an aqueous solution $(18 \mathrm{mg} / \mathrm{ml})$ at $4{ }^{\circ} \mathrm{C}$. A diluted solution of $1 \mu \mathrm{g} / \mathrm{ml}$ was used to inoculate the fourth and fifth leaves of tobacco by rubbing the leaf lamina with a finger dipped in inoculum mixed with diatomaceous earth as an abrasive (10). $P$. parasitica var. nicotianae was propagated on potato dextrose agar (PDA) plates at $27^{\circ} \mathrm{C}$ and maintained on slants at $4^{\circ} \mathrm{C}$. A spore suspension of $5 \times 10^{6}$ spores $/ \mathrm{ml}$ was used to inoculate the sixth and seventh leaves of tobacco by infiltrating leaf intercellular spaces. Pectobacterium carotovorum subsp. carotovorum was cultured on nutrient agar medium plates at $25^{\circ} \mathrm{C}$ and maintained in aqueous glycerol suspension at $-76^{\circ} \mathrm{C}$. The bacterial suspension of $5 \times 10^{6} \mathrm{CFU} / \mathrm{ml}$ was used to inoculate the sixth and seventh leaves of tobacco by placing $25-\mu$ d drops on two sites on the upper leaf surfaces.

Determination of plant gene expression. Reverse-transcriptase polymerase chain reaction (RT-PCR) was used to determine expression of $O s L S$ and plant defense-related genes. Total RNA was isolated from top two growing leaves of tobacco using the Tri Reagent Kit (Sigma-Aldrich [Shanghai] Trading Co., Ltd., Shanghai, China). First-strand cDNA was synthesized from $2 \mu \mathrm{g}$ of RNA using the superscript II RNAse $\mathrm{H}^{-}$Reverse Transcriptase (Invitrogen Biotechnology [Shanghai] Trading Co., Ltd., Shanghai, China) and specific primers (Table 1). The constitutively expressed EFI $\alpha$ gene was used as a loading and amplification control. RT-PCR products were confirmed by sequencing. Real-time RT-PCR was quantitated as described (21) using EFI $\alpha$ as a control (26). Reactions of $25 \mu$ l contained $1 \mu \mathrm{l}$ of $1 / 10$ diluted first-strand cDNA, $2.5 \mu \mathrm{M}$ each primer, and $1 \times$ SYBR Premix Ex Taq (TaKaRa Biotechnology [Dalian] Co., Ltd., Dalian, Liaoning Province, China]. All reactions were performed in triplicates with null-template controls in which RNA was absent.

Plant resistance evaluation. Plants were investigated 5 days after inoculation with $P$. carotovorum subsp. carotovorum and 7 days after inoculation with TMV and Phytophthora parasitica var. nicotianae, respectively. Soft rot symptoms caused by Pectobacterium carotovorum subsp. carotovorum were observed directly. The number of necrotic lesions caused by TMV on an inoculated leaf was counted, and the ratio of lesion area to leaf size was surveyed as a score of symptom severity. Necrotic

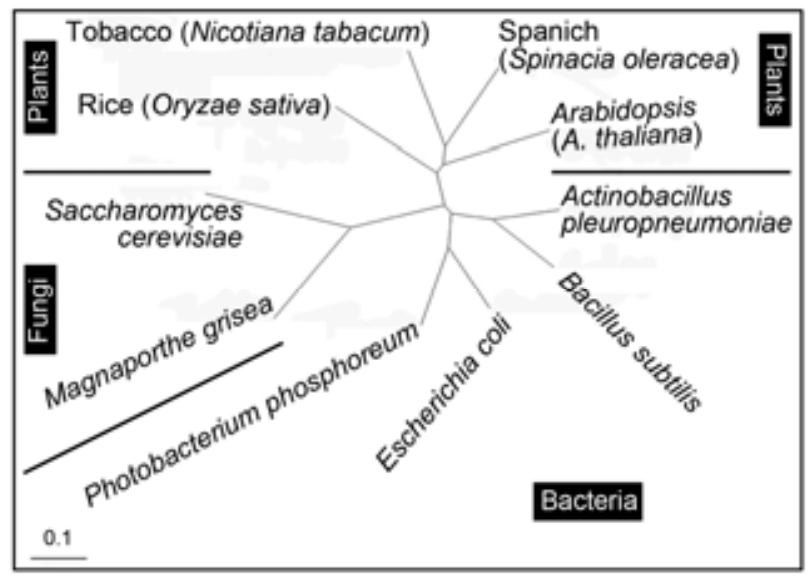

Fig. 2. Phylogenetic tree of amino acid sequences of lumazine synthases from higher plants (Oryzae sativa, Arabidopsis thaliana, Spinacia oleracea, and Nicotiana tabacum) and microorganisms (Saccharomyces cerevisiae, Magnaporthe grisea, Actinobacillus pleuropneumoniae, Photobacterium phosphoreum, Bacillus subtilis, and Escherichia coli). The phylogenetic tree was built with the DNAstar ClustalW program. Scale bar of relation degree is shown on left bottom corner.

TABLE 1. Information about genes tested in this study

\begin{tabular}{|c|c|c|c|}
\hline Gene & GenBank accession no. & Primers & Product size (bp) \\
\hline \multirow[t]{2}{*}{ OsLS } & GQ202237 & 5'-GCGGATCCATGGCGGCGGCTGC-3' & \\
\hline & & 5'-GCGTCGACTCAGGCCAGGTGATGCT-3' & 682 \\
\hline NPR1 & AF480488 & 5'-GTAGTAAGGTGGAATTGAAGGAGG-3' & \\
\hline \multirow[t]{2}{*}{$P R-1 a$} & X05959 & 5'-CCTAGTAATATCCCACTCTTGCC-3' & \\
\hline & & 5'-CTCCATTGTTACACTGAACCCTAG -3' & 384 \\
\hline \multirow[t]{2}{*}{$P R-1 b$} & X66942 & 5'-ATGGGATACTCCACAACAT-3' & \\
\hline & & 5'-TTACTAGACATCAGTTGGGAAG-3' & 537 \\
\hline \multirow[t]{2}{*}{$E F 1 \alpha$} & AF120093 & 5'-AGACCACCAAGTACTACTGCAC-3' & \\
\hline & & 5'-CCACCAATCTTGTACACATCC-3' & 495 \\
\hline
\end{tabular}


lesions caused by Phytophthora parasitica var. nicotianae were investigated and the ratio of lesion area to infiltrated leaf size was surveyed as a score of symptom severity. Symptom severities were compared between WT and transgenic plants to evaluate levels of resistance to the pathogens.

Statistical analysis. All experiments were done at least three times with similar results, and each time with 15 equivalent plants. The Student's $t$ test $(P<0.01)$ was used to compare data obtained from WT with those obtained from each line of transgenic plants. Quantitative data were also analyzed by the analysis of variance (ANOVA) test $(P<0.01)$ to compare differences among different lines of transgenic plants.

Data deposition. The $O S L S$ sequence was deposited in the GenBank database under accession no. GQ202237.

\section{RESULTS}

Analyses of the $O \boldsymbol{s} L S$ gene and protein. The IRGSP database annotated $O S J N B a 0067 K 08.20$ as a candidate for the rice gene for LS, OsLS. The gene cloned in this study from a japonica rice cultivar contains $666 \mathrm{bp}$ and encodes a protein of 221 amino acids (GenBank accession no. GQ202237). The amino acid sequence predicted from the cloned $O s L S$ gene was identical to that predicted for OSJNBa0067K08.20, except that amino acid 225 was predicted to be threonine in OsLS and cysteine in OSJNBa0067K08.20. Phylogenetic analysis showed that the predicted OsLS protein is closer to higher plant LS than microbial LS (Fig. 2). Based on amino acid sequence, the predicted OsLS protein is 32 to $49 \%$ identical to its microbial counterparts (Fig. $3 \mathrm{~A})$ and 68 to $75 \%$ identical to the spinach, tobacco, and Arabidopsis homologs (Fig. 3B). An His-OsLS fusion protein was produced in bacteria and was purified by chromatography (e-Xtra). The molecular weight of the fusion protein was estimated to be $29.81 \mathrm{kDa}$ but appeared slightly larger by T-SDSPAGE (e-Xtra). Similar discrepancies are often observed with His-tagged proteins because the extra positive charge is not completely eliminated by SDS, causing retardation of the fusion protein on SDS-PAGE (45).

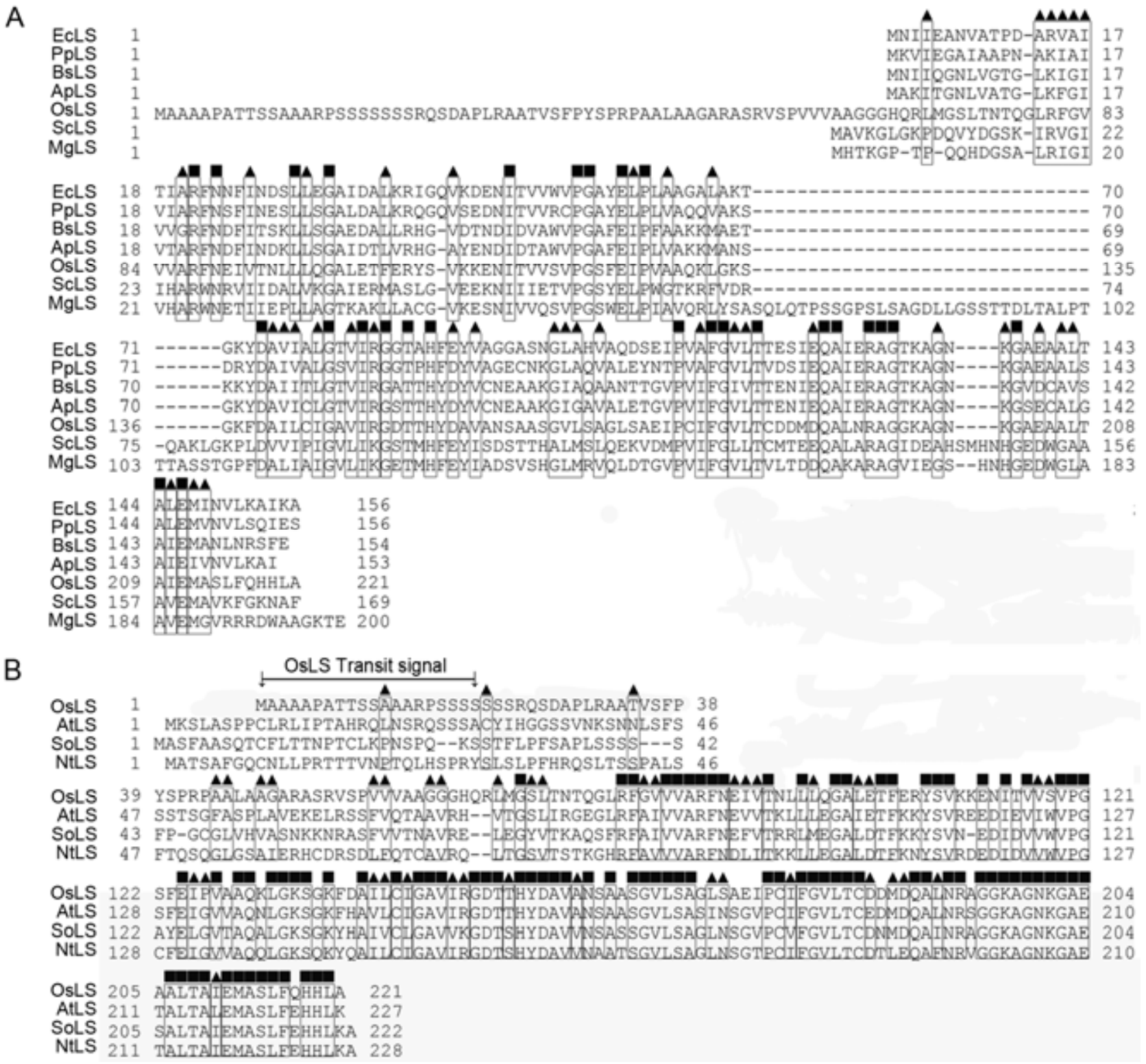

Fig. 3. Alignments of lumazine synthase $(L S)$ homologues. Identical amino acid residues are indicated by filled black squares and amino acids for which the majorities are identical are indicated by filled black triangles. A, Amino acid sequence alignment of Oryzae sativa LS (OsLS) with its microbial counterparts, EcLS, PpLS, BsLS, ApLS, ScLS, and MgLS from Escherichia coli, Photobacterium phosphoreum, Bacillus subtilis, Actinobacillus pleuropneumoniae, Saccharomyces cerevisiae, and Magnaporthe grisea, respectively. B, Amino acid sequence alignment of OsLS with its homologues AtLS, SoLS, and NtLS from Arabidopsis, spinach, and tobacco, respectively. The chloroplast-directed transit signal is indicated for the OsLS sequence. 
Ectopic expression of $O s L S$ in transgenic tobacco. Transformation of tobacco with pBI121::35S::OsLS generated OsLSexpressing transgenic tobacco (LSETT), and transformation with pBI121::35S created transgenic plants with WT characteristics that were considered WT for this study (e-Xtra). Three representative LSETT lines were arbitrarily designated LSETT1, LSETT2, and LSETT3. They were characterized in comparison with WT. PCR detected the presence of the OsLS gene in LSETT1, LSETT2, and LSETT3 (e-Xtra). Southern blot analysis indicated
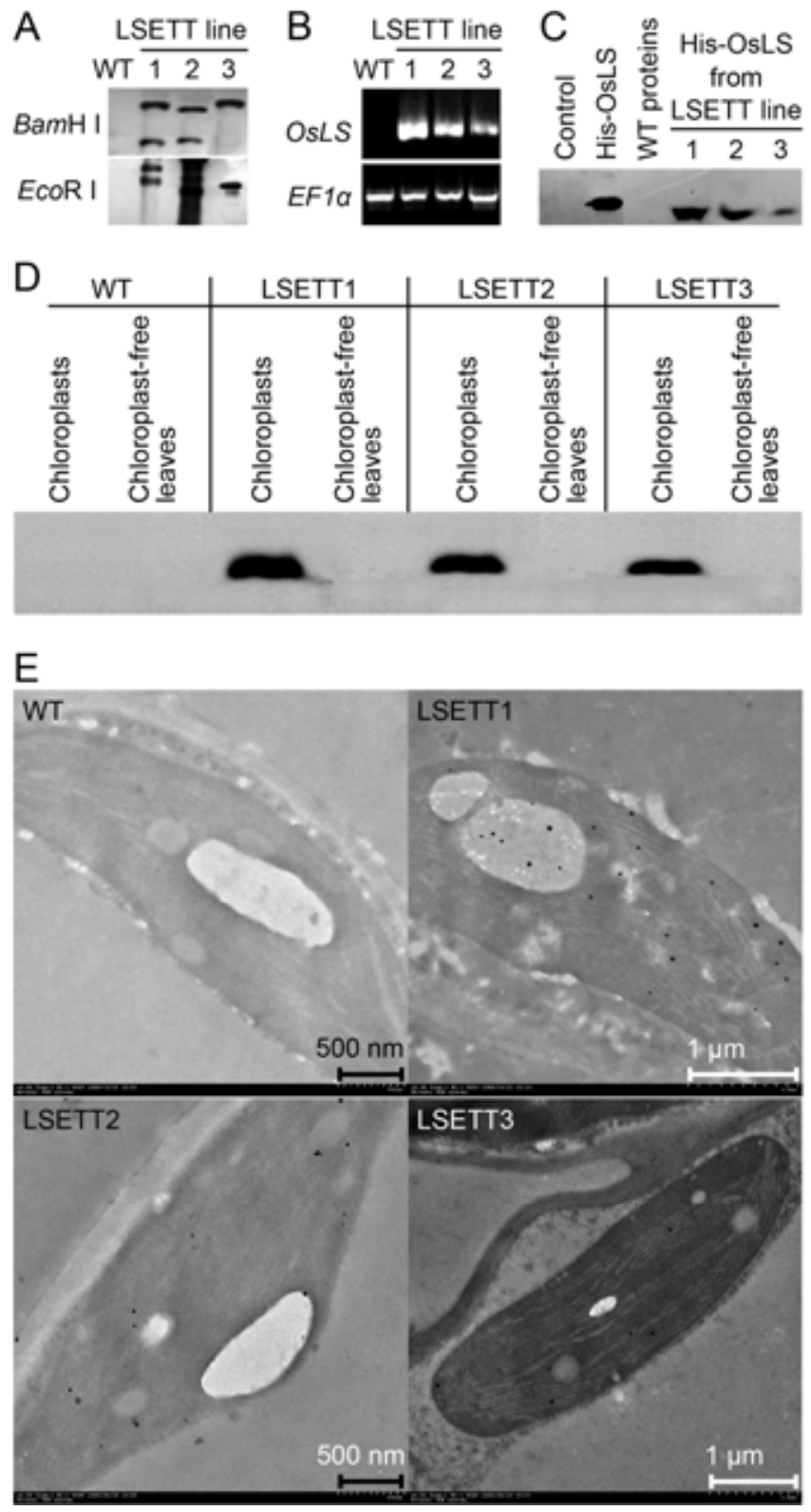

Fig. 4. Characterization of Oryzae sativa lumazine synthase (OsLS)-expressing transgenic tobacco (LSETT) plants and chloroplast localization of the OsLS protein. A, Southern blot analysis of genomic DNA from LSETT1 and the wild type (WT). DNA was restriction digested and the blot was hybridized with an $O s L S$ probe. B, Reverse-transcriptase polymerase chain reaction analysis using RNA from WT and LSETT lines. The EFl $\alpha$ gene was used to verify uniform loading and amplification of RNA samples. C, Western blot hybridized with anti-OsLS antibody and detected with secondary antibody conjugated to horseradish peroxidase. Protein samples are indicated, and phosphate buffer (0.02 M, pH7.6) was used as a control. D, Western blot hybridized with anti-OsLS and detected with secondary antibody conjugated to horseradish peroxidase. Plant sources of protein samples are indicated. Protein samples were from leaf chloroplasts and leaves in which chloroplasts had been removed. E, Immune colloidal gold assay showing OsLS in chloroplasts of the LSETT lines but not the WT. two copies of $O s L S$ in LSETT1 and LSETT3 and three copies of the gene in LSETT2 (Fig. 4A). RT-PCR detected evident expression of the $O s L S$ gene in LSETT plants (Fig. 4B). Real-time RTPCR revealed the greatest, moderate, and minimal levels of the OsLS expression in LSETT1, LSETT2, and LSETT3 (Fig. 5A), and the difference was significant (ANOVA test, $P<0.01$ ). Consistently, western blot showed optimal, moderate, and minimal amounts of the OsLS protein in LSETT1, LSETT2, and LSETT3 (Fig. 4C).

OsLS localizes to chloroplasts. Prediction with the Hiden Markov Models from the SignalP.3.0 Server program suggested a chloroplast-directed transit signal consisting of 1 to 20 amino acid residues in the OsLS sequence (Fig. 3B). The Targetp V1.1 program predicted the probability of OsLS localization to the chloroplast as 0.879 , in contrast to probabilities of 0.379 and 0.025 for localization to mitochondria or other subcellular sites. Localization was confirmed by western blot and immune colloidal gold assay. The western blot detected OsLS in chloroplasts from LSETT1, LSETT2, and LSETT3 but not in WT or in protein samples isolated from LSETT leaves in which chloroplasts were removed (Fig. 4D). By immune colloidal gold assay, OsLS was found exclusively in chloroplasts in the three LSETT lines tested in contrast to WT (Fig. 4E). Apparently, OsLS was distributed over the organelle and sometimes was associated with granulose.

Flavin, JA, and ethylene levels are elevated coordinately in LSETT. Consistent with the assumption that the ectopic OsLS production might substantially impact the production of flavins, levels of free RIB, FMN, and FAD were greatly elevated in LSETT1, LSETT2, and LSETT3 compared with WT (Fig. 5B). RIB, FMN, and FAD were 2.6-fold, 1.9-fold, and 2.6-fold higher in LSETT1 than in WT. Moreover, compared with WT, LSETT2
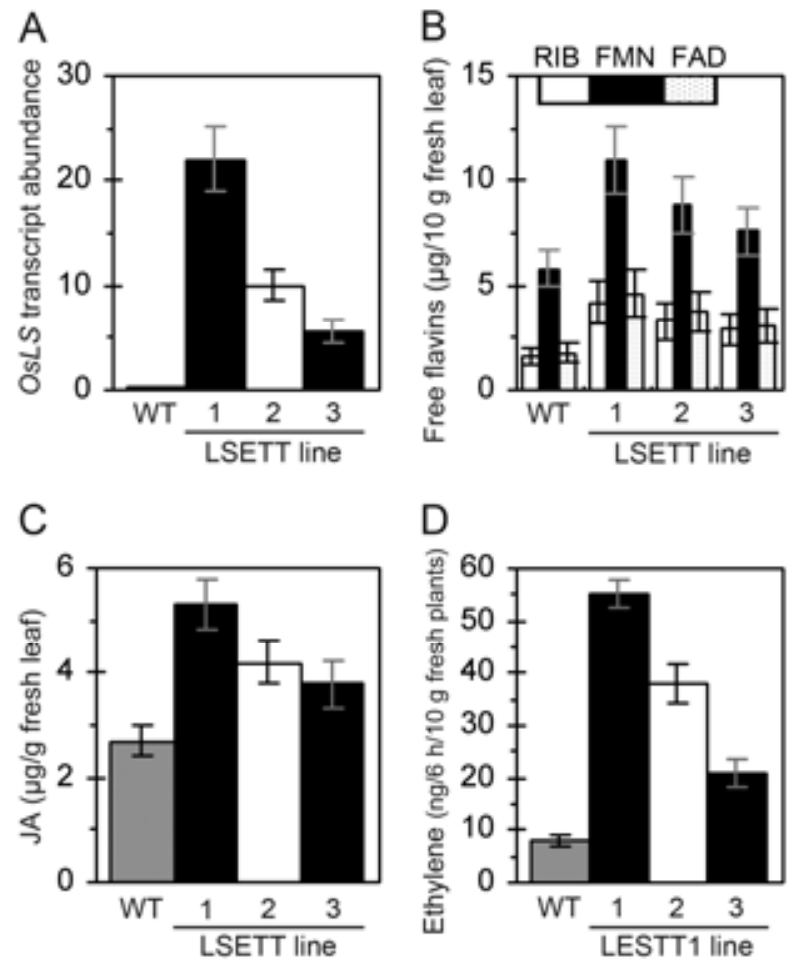

Fig. 5. Comparative tests of Oryzae sativa lumazine synthase (OsLS)expressing transgenic tobacco (LSETT) lines and the wild type (WT) in the effects of the $O s L S$ expression and levels of flavins (riboflavin [RIB], flavin mononucleotide [FMN], and flavin adenine dinucleotide [FAD]), jasmonic acid (JA), and ethylene. A, Real-time reverse-transcriptase polymerase chain reaction quantification of $O S L S$ transcript. Transcript abundance was defined as 1 for the WT and was scored accordingly for the LSETT lines. B to D, Free flavin content and levels of JA and ethylene. All data are means \pm standard deviation bars ( $n=45$ plants). 
had 2.1-fold higher RIB, 1.5-fold higher FMN, and 2.1-fold higher FAD; and LSETT3 had 1.8-fold higher RIB, 1.3-fold higher FMN, and 1.7-fold higher FAD. Differences in flavin content were significant when each LSETT line was compared with WT (Student's $t$ test, $P<0.01$ ) and the three LSETT lines were compared (ANOVA test, $P<0.01$ ). We next studied whether changes in flavin content affected levels of JA and ethylene, both of which mediate plant responses to abiotic and biotic stress $(1,2,9-11,19,29,40)$. We found that levels of JA and ethylene were highly elevated in LSETT plants compared with WT. Levels of JA were 2-fold, 1.6-fold, and 1.4-fold higher in LSETT1, LSETT2, and LSETT3, respectively, than in WT (Fig. 5C). Levels of ethylene were 6.9-fold, 4.8-fold, and 2.6-fold higher in LSETT1, LSETT2, and LSETT3, respectively, than in WT (Fig. 5D). Differences in JA and ethylene levels were significant when each LSETT line was compared with WT (Student's $t$ test, $P<0.01$ ) and the three LSETT lines were compared (ANOVA test, $P<$ 0.01 ). Evidently, levels of flavins, JA, and ethylene were consistent with extents of $O s L S$ expression.
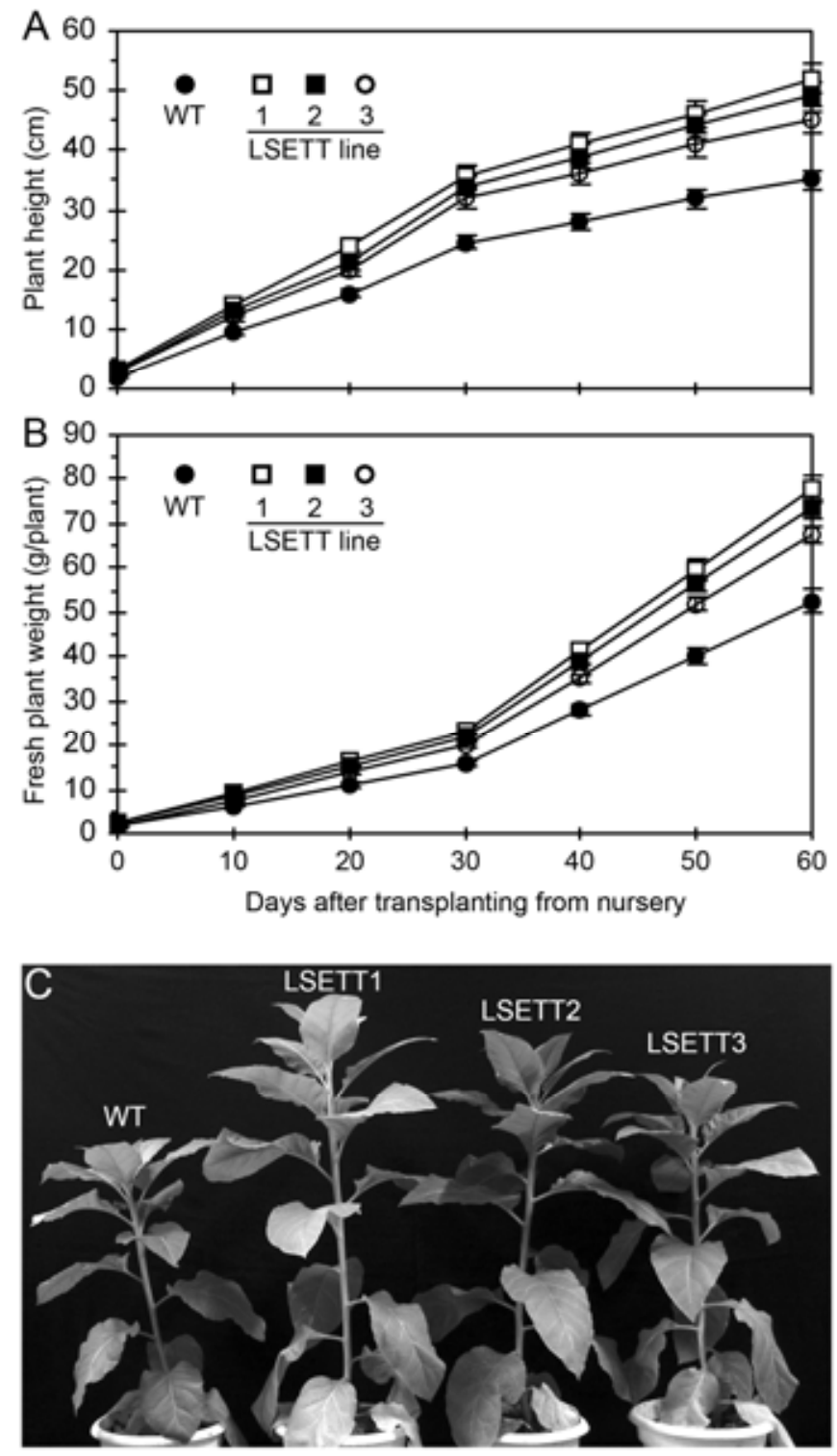

Fig. 6. Plant growth monitoring. Plants were transplanted from a nursery and were grown in the greenhouse. $\mathrm{WT}=$ wild type and LSETT $=$ Oryzae sativa lumazine synthase $(O s L S)$-expressing transgenic tobacco lines. A and B, Plant height and weight determined as means \pm standard deviation bars $(n=90$ plants). C, Appearance of 75-day-old plants (60 days after transplanting from nursery).
LSETT growth is enhanced. Growth enhancement was characterized as one of the phenotypic characteristics of LSETT plants compared with the WT (e-Xtra). Plant height (Fig. 6A) and fresh weight (Fig. 6B) were monitored at intervals subsequent to transplanting from the nursery. LSETT and WT were similar in plant shape (Fig. 6C; $e$-Xtra). Compared with WT, however, LSETT1, LSETT2, and LSETT3 were 1.2-fold to 1.5-fold greater in plant height and weight during the stage of vegetative growth, and the differences between each LSETT line and WT was significant (Student's $t$ test, $P<0.01$ ). However, when the three LSETT lines were compared, differences in plant height and weight were significant between LSETT1 and LSETT3 but not significant between LSETT1 and LSETT2 or between LSETT2 and LSETT3 (ANOVA test, $P<0.01$ ). Comparatively, LSETT1 growth was enhanced significantly compared with WT, LSETT2, and LSETT3 (Fig. 6A to C), and growth extents were consistent with levels of the OsLS expression, flavins, JA, and ethylene (Fig. 5) in the three LSETT lines.

Pathogen inoculation induces expression of defense-related genes in LSETT1. Enhanced defense as an important characteristic of LSETT plants was found initially when LSETT1 and WT were compared in pathogen-induced expression of defenserelated genes, including several defense response genes and the NPRl gene that is involved in regulating systemic acquired resistance $(3,4,11)$. Defense responses were evaluated with TMV, Pectobacterium carotovorum subsp. carotovorum, and Phytophthora parasitica var. nicotianae viral, bacterial, and oomycete pathogens of tobacco. LSETT1 was first investigated because it supported strong OsLS expression (Fig. 5A). LSETT1 also supported higher expression of defense-related genes than the WT
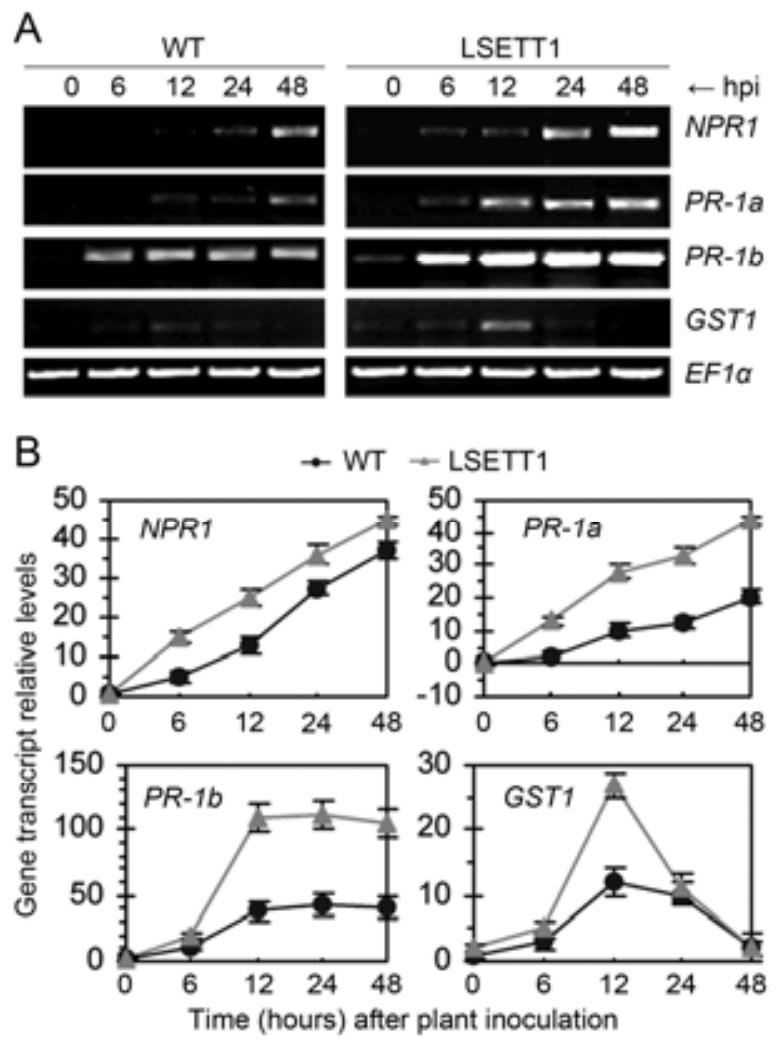

Fig. 7. Expression of defense-related genes in plants responding to Tobacco mosaic virus $(\mathrm{TMV}) . \mathrm{WT}=$ wild type and LSETT $=$ Oryzae sativa lumazine synthase $(O s L S)$-expressing transgenic tobacco lines. A, Reverse-transcriptase polymerase chain reaction (RT-PCR) time course of defense-related gene expression at the indicated times at hours post inoculation (hpi). B, Real-time RT-PCR for gene expression. For each gene, transcript abundance was defined as 1 for $0 \mathrm{~h}$ (immediately after plant inoculation) and was scored accordingly for other intervals. Data are means \pm standard deviation bars $(n=45$ plants $)$. 
following inoculation with TMV (Fig. 7A). Amounts of NPR1, $P R-1 a$, and $P R-1 b$ transcripts accumulated during 6 to $48 \mathrm{~h}$ (Fig. $7 \mathrm{~B}$ ) and the amount of GST1 transcript at $12 \mathrm{~h}$ after plant inoculation were much higher in LSETT1 than in the WT (Fig. 7B) (Student's $t$ test, $P<0.01$ ). In particular, the expression of $P R-1 a$, the most frequently studied defense response gene $(3-5,7,10$, 20,25,26,46), exhibited a typical course of time after LESTT1 inoculation with TMV. PR-1a also responded to Pectobacterium carotovorum subsp. carotovorum and Phytophthora parasitica var. nicotianae. Both pathogens induced greater expression of the gene in LSETT1 than in WT tested at $24 \mathrm{~h}$ after inoculation (e-Xtra).

LSETT1 resists pathogens. Enhanced expression of defenserelated genes was correlated with plant resistance to the three pathogens. TMV causes necrosis on inoculated leaves of tobacco. The necrosis was much less severe in leaves from LSETT1 than from WT at 7 days after inoculation (Fig. 8A). The ratio of necrotic area to leaf size was significantly smaller for LSETT1

A
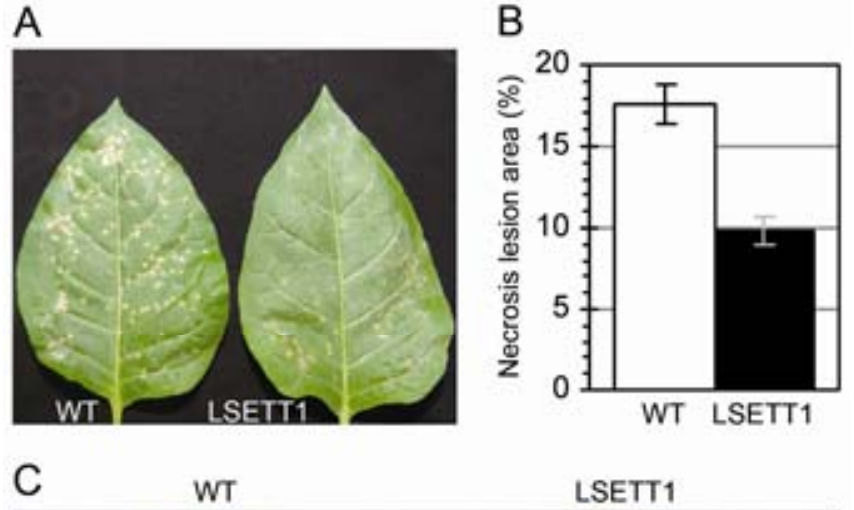

WT
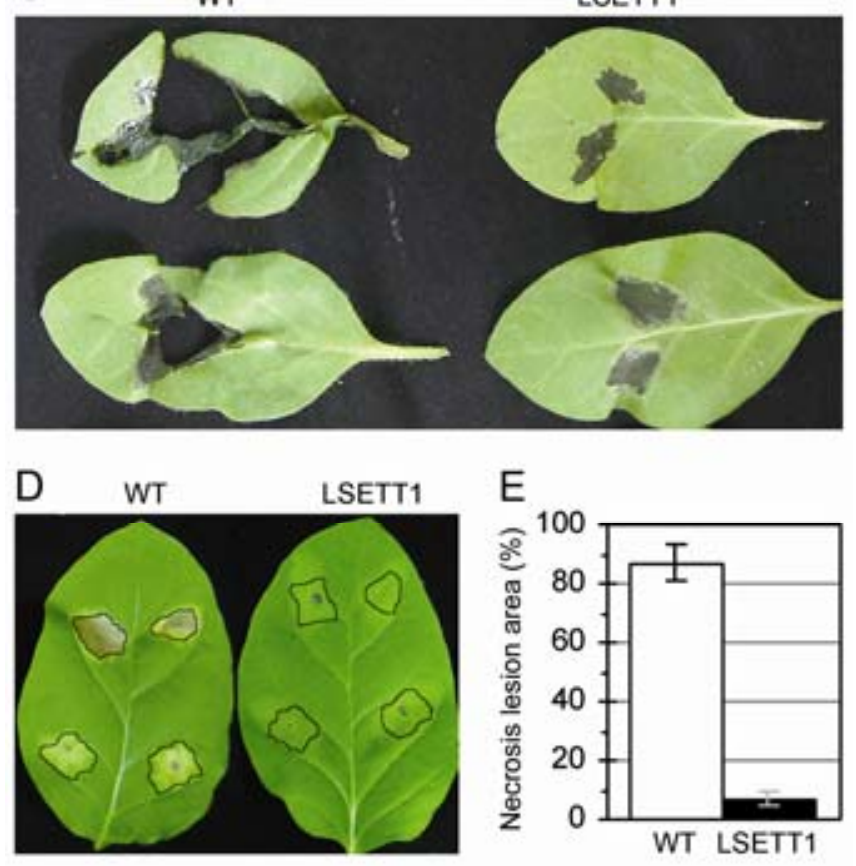

Fig. 8. Plant responses to pathogens. WT $=$ wild type and LSETT $=$ Oryzae sativa lumazine synthase $(O s L S)$-expressing transgenic tobacco lines. A, Leaves photographed 7 days after inoculation with Tobacco mosaic virus (TMV). B, TMV-induced necrotic lesion area as a percentage of leaf size. $\mathbf{C}$, Leaves photographed 5 days after inoculation with the bacterial pathogen Pectobacterium carotovorum subsp. carotovorum. D, Leaves photographed 7 days after inoculation with the oomycete pathogen Phytophthora parasitica var. nicotianae. Inoculation was done by infiltrating leaf intercellular spaces with a spore suspension of the oomycete. Infiltrated leaf areas are bordered. E, $P$. parasitica var. nicotianae-induced necrotic lesion area as a percentage of infiltrated leaf area. B and D, Data are means \pm standard deviation bars $(n=$ 45 plants). leaves than WT leaves (Student's $t$ test, $P<0.01$ ) (Fig. 8B). Pectobacterium carotovorum subsp. carotovorum causes hollow stalk and also causes leaf soft rot symptoms in tobacco. Soft rot symptoms were much less severe in leaves from LSETT1 than from the WT at 5 days after inoculation (Fig. 8C). Phytophthora parasitica var. nicotianae is the pathogen of tobacco black shank and causes necrotic lesions on leaves of the plant. Necrotic lesions were induced on leaves infiltrated with a spore suspension of the oomycete. The oomycete-induced necrosis was much less severe in leaves from LSETT1 than from the WT at 7 days after inoculation (Fig. 8D). The ratio of necrotic area to infiltrated leaf size was smaller for LSETT1 leaves than WT leaves (Student's $t$ test, $P<0.01$ ) (Fig. 8E). Alleviated symptom severities suggested resistance enhanced in LSETT1.

Defense correlates with $O \boldsymbol{S} L S$ expression. In responses to the pathogens, LSETT1, LSETT2, and LSETT3 supported the highest, moderate, and the lowest expression, respectively, of defenserelated genes (Fig. 9A; $e$-Xtra). LSETT1, LSETT2, and LSETT3

A
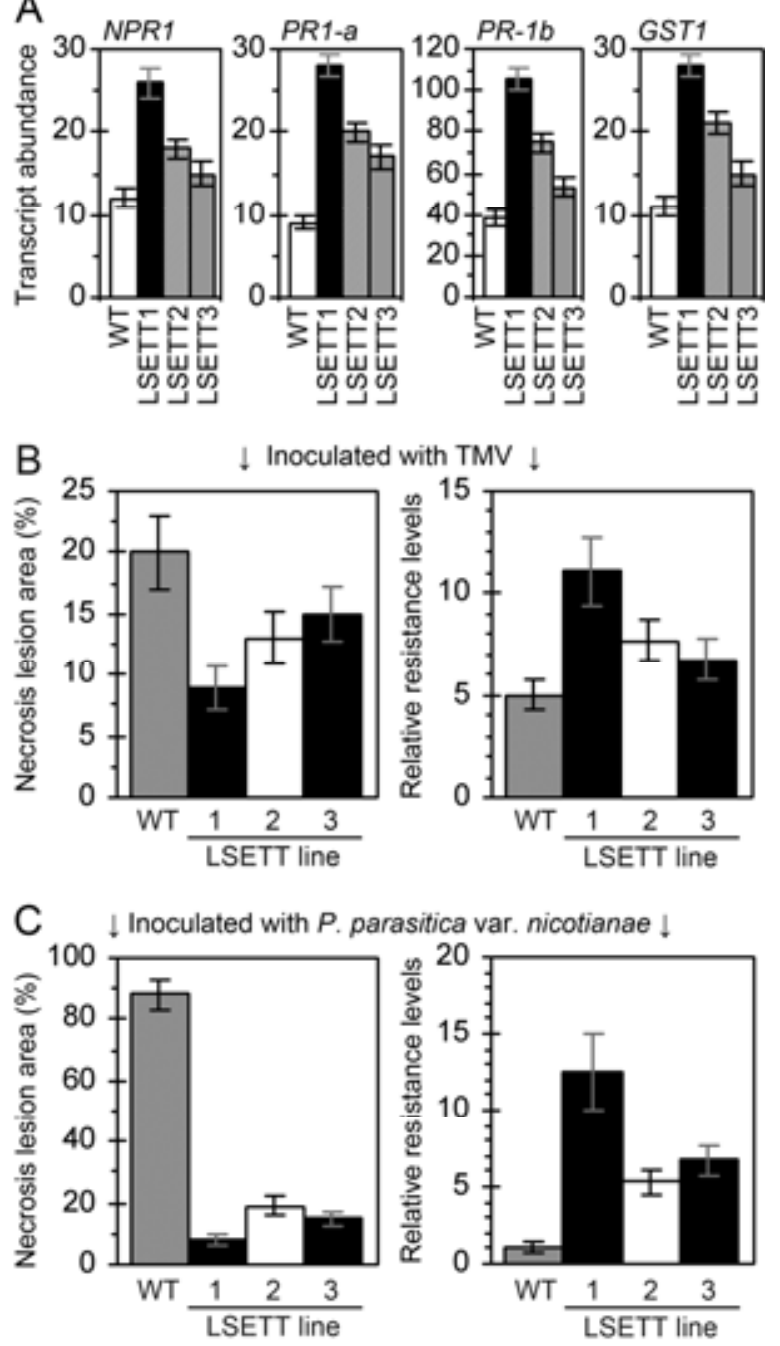

Fig. 9. Comparative tests of Oryzae sativa lumazine synthase (OsLS)expressing transgenic tobacco (LSETT) lines and the wild type (WT) in defense responses. A, Expression of defense-related genes in plants inoculated with Tobacco mosaic virus (TMV). RNA samples isolated at 0 and $12 \mathrm{~h}$ were subjected to real-time reverse-transcriptase polymerase chain reaction. Abundance of a transcript was defined as 1 for $0 \mathrm{~h}$, and relative level of the transcript was determined accordingly. B, TMV-induced necrotic lesion area as a percentage of leaf size and relative resistance as centuplicate reciprocal value of lesion area to leaf size ratio. C, Phytophthora parasitica var. nicotianae-induced necrotic lesion area as a percentage of leaf size and relative resistance as centuplicate reciprocal value of lesion area to inoculated leaf size ratio. All data are means \pm standard deviation bars ( $n=45$ plants). 
showed different levels of resistance to TMV and $P$. parasitica var. nicotianae. Based on the ratios of TMV-induced lesion areas to leaf areas, the LSETT lines were more resistant than the WT to the viral pathogen (Fig. 9B, left panel). Based on the ratios of $P$. parasitica var. nicotianae-induced lesion areas to inoculated leaf areas, the LSETT lines were more resistant than the WT to the oomycete (Fig. 9C, left panel). Based on centuplicate reciprocal values of lesion area to leaf size ratio (Fig. 9B, right panel) and lesion area to inoculated leaf area (Fig. 9C, right panel), resistance levels were greatest, moderate, and smallest in LSETT1, LSETT2, and LSETT3, respectively. This result suggested that defense responses correlated with extents of the $O s L S$ expression and correlated with increases in flavin, JA, and ethylene content (Fig. 5).

\section{DISCUSSION}

We cloned the rice $O S L S$ gene, introduced it into tobacco, and generated LSETT plants. Then, we investigated LSETT to determine whether LS plays a role in tobacco defense responses to three species of pathogens. Replicated experiments have yielded several results. First, ectopic expression of the OsLS gene effectively alters flavin content in transgenic tobacco. Second, modulation of flavin content in this way contributes to defense responses in the plant. Third, in addition to inducing pathogen resistance, the ectopic $O S L S$ expression also enhances plant growth. Both types of $O s L S$-conferred phenotypes correlate with increases in JA and ethylene levels. Our results suggest that $L S$ plays a role in plant defense responses. Previous studies have demonstrated that the extrinsic application of RIB induces plant resistance to pathogens $(10,46)$. In comparison, results obtained in this study are convincing in that the intrinsic modulation of flavin content participates in regulation of defense responses.

We began with cloning and analysis of $O s L S$ because no studies have investigated LS in staple crop plants, such as rice, although LS has been identified in many microbial species $(17,36)$ and a few species of higher plants, including spinach (Spinacia oleracea), tobacco, and Arabidopsis $(13,18,32,34)$. LS genes identified in these organisms share different extents of similarity in nucleotide sequences $(13,18,32,34)$. Based on our bioinformatics analysis, the $O s L S$ gene cloned in this study from a japonica rice cultivar has strong identity with its homologues in higher plants and less homology to microbial orthologues.

Our results demonstrate the ectopic $O s L S$ expression and the production of the OsLS protein in LSETT plants. Chloroplast localization of OsLS observed in this study is consistent with previous evidence that all plant LS proteins identified so far localize to chloroplasts $(13,18,32,34)$. Because RIB biosynthesis and reactions for flavin form conversions are also predicted to occur mainly in the organelle $(18,13,32,34)$, the chloroplast localization of OsLS permits the possibility for flavin content to change at the right place. The coincident increases in levels of free RIB, FMN, and FAD conform to dynamics of flavin form conversions. RIB and FMN conversion is reversible $(31,34)$, whereas FMN to FAD conversion is irreversible (22). The accumulation of a particular flavin form is concentration dependent; therefore, a larger amount of free RIB or FMN results in a greater amount of FMN or FAD (31). Because RIB biosynthesis is a prerequisite for the subsequent flavin-producing steps, the change in RIB content has an initial role in modulating FMN and FAD concentrations.

Our evidence further demonstrates that the ectopic OsLS expression and increases in free flavin content accompany elevation in JA and ethylene levels, and these changes correlate with growth enhancement and pathogen resistance in LSETT lines. Although the acquisition of both phenotypes conforms in general to functions of JA and ethylene in regulation of plant growth and defenses $(1,2,9,11,19,40,44)$, we do not have evidence yet to elucidate functional relationships between LS, JA, and ethylene. Instead, we have focused on defense responses toward TMV, Pectobacterium carotovorum subsp. carotovorum, and Phytophthora parasitica var. nicotianae viral, bacterial, and oomycete pathogens of tobacco. Consistent with the dogma that JA and ethylene differentially affect resistance against pathogens with different lifestyles $(11,38)$, levels of resistance to the different pathogens correlate with levels of JA and ethylene in the three LSETT lines. In Arabidopsis, LS (synonym COS1) inhibits transduction of the JA signal (44), which normally is synergistic with ethylene to regulate plant defense responses (11). In plants under abiotic or biotic stress, JA and ethylene levels often increase concomitantly to trigger defensive pathways $(9,11,15$, 40). Defensive pathways are apparently activated in LSETT plants because they have evident expression of defense response genes and resist the viral, bacterial, and oomycete pathogens.

In conclusion, the ectopic expression of $O s L S$ in tobacco causes a concomitant elevation in flavin content, levels of JA and ethylene, and levels of resistance to pathogens. The physiological relationships between these responses will be the subject of future studies.

\section{ACKNOWLEDGMENTS}

This study was supported by the National Science Foundation for Distinguished Young Scholars (30525008), the Novel Transgenic Organisms Breeding Project (2009ZX08002-004B) and the Natural Science Foundation (30771441) in China.

\section{LITERATURE CITED}

1. Abeles, F. B., Morgan, P. W., and Saltveit, M. E., Jr. 2004. Ethylene in Plant Biology, second ed. Academic Press, New York.

2. Bleecker, B., and Kende, H. 2000. Ethylene: A gaseous signal molecule in plants. Annu. Rev. Cell Dev. Biol. 16:1-18.

3. Cao, H., Bowling, S. A., Gordon, A. S., and Dong, X. 1994. Characterization of an Arabidopsis mutant that is nonresponsive to inducers of systemic acquired resistance. Plant Cell 8:1583-1592.

4. Cao, H., Glazebrook, J., Clarke, J. D., Volko, S., and Dong, X. 1997. The Arabidopsis NPR1 gene that controls systemic acquired resistance encodes a novel protein containing ankyrin repeats. Cell 88:57-63.

5. Chen, L., Qian, J., Qu, S., Long, J., Yin, Q., Zhang, C., Wu, X., Sun, F., Wu, T., Hayes, M., Beer, S. V., and Dong, H. 2008. Identification of specific fragments of $\mathrm{HpaG}_{\mathrm{Xooc}}$, a harpin protein from Xanthomonas oryzae pv. oryzicola, that induce disease resistance and enhanced growth in rice. Phytopathology 98:781-791.

6. Dawson, K. R., Unklesbay, N. F., and Hedrick, H. B. 1988. HPLC determination of riboflavin, niacin, and thiamin in beef, pork, and lamb after alternate heat-processing methods. J. Agric. Food Chem. 36:11761179.

7. Delaney, T. P., Uknes, S., Vernooij, B., Friedrich, L., Weymann, K., and Negrotto, D. 1994. A central role of salicylic acid in plant disease resistance. Science 266:1247-1250.

8. de Souza, A. C., Kodach, L., Gadelha, F. R., Bos, C. L., Cavagis, A. D., Aoyama, H., Peppelenbosch, M. P., and Ferreira, C. V. 2006. A promising action of riboflavin as a mediator of leukaemia cell death. Apoptosis 11:1761-1771.

9. Dong, H. P., Peng, J., Bao, Z., Meng, X., Bonasera, J. M., Chen, G., Beer, S. V., and Dong, H. 2004. Downstream divergence of the ethylene signaling pathway for harpin-stimulated Arabidopsis growth and insect defense. Plant Physiol. 136:3628-3638.

10. Dong, H. S., and Beer, S. V. 2000. Riboflavin induces disease resistance in plants by activating a novel signal transduction pathway. Phytopathology 90:801-811.

11. Dong, X. 1998. SA, JA, ethylene, and disease resistance in plants. Curr. Opin. Plant Biol. 1:316-323.

12. Dutilleul, C., Garmier, M., Noctor, G., Mathieu, C., Chetrit, P., Foyer, C. H., and de Paepe, R. 2003. Leaf mitochondria modulate whole cell redox homeostasis, set antioxidant capacity, and determine stress resistance through altered signaling and diurnal regulation. Plant Cell 15:1212-1226.

13. Fischer, M., and Bacher, A. 2008. Biosynthesis of vitamin B2: Structure and mechanism of riboflavin synthase. Arch. Biochem. Biophys. 474:252-265.

14. Frens, G. 1973. Controlled nucleation for the regulation of the particle size in monodisperse gold solution. Natl. Phys. Sci. 241:20-22. 
15. Guzmàn, P., and Ecker, J. R. 1990. Exploiting the triple response of Arabidopsis to identify ethylene-related mutants. Plant Cell 2:513-523.

16. Hodges, G. M., Smolira, M. A., and Livington, D. C. 1984. Scanning electron microscope immuno-cytochemistry in practice. Pages 129-142 in: Immunolabelling for Electron Microscopy. J. M. Polak and M. Varndell, eds. Elsevier Science Publisher, Amsterdam.

17. Huang, S. N., and Swaan, P. W. 2000. Involvement of a receptor-mediated component in cellular translocation of riboflavin. J. Pharm. Exp. Therap. 294:117-125.

18. Jordan, D. B., Bacot, K. O., Carlson, T. J., Kessel, M., and Viitanen, P. V. 1999. Plant riboflavin biosynthesis. Cloning, chloroplast localization, expression, purification, and partial characterization of spinach lumazine synthase. J. Biol. Chem. 274:22114-22121.

19. Kendrick, M. D., and Chang, C. 2008. Ethylene signaling: New levels of complexity and regulation. Curr. Opin. Plant Biol. 11:479-485.

20. Liu, F., Liu, H., Jia, Q., Wu, X., Guo, X., Zhang, S., Song, F., and Dong, H.S. 2006. The internal glycine-rich motif and cysteine suppress several effects of $\mathrm{HpaG}_{\text {Xooc }}$ in plants. Phytopathology 96:1052-1059.

21. Livak, K. J., and Schmittgen, T. D. 2001. Analysis of relative gene expression data using real-time quantitative PCR and the $2^{-\Delta \Delta C_{T}}$ method. Methods 25:402-408.

22. McCormick, D. B., and Wright, L. D. 1980. Vitamins and Coenzymes. Academic Press, New York.

23. Mori, T., and Sakurai, E. 1996. Riboflavin affects anthocyanin synthesis in nitrogen culture using strawberry suspended cells. J. Food Sci. 61:698-702.

24. Noctor, G., de Paepe, R., and Foyer, C. H. 2007. Mitochondrial redox biology and homeostasis in plants. Trends Plant Sci. 12:125-134.

25. Peng, J. L., Bao, Z. L., Dong, H. S., Ren, H. Y., and Wang, J. 2004. Expression of harpin $\mathrm{Xoo}_{\mathrm{O}}$ in transgenic tobacco induces pathogen defense in the absence of hypersensitive cell death. Phytopathology 94:1048-1055.

26. Peng, J. L., Dong, H. S., Dong, H. P., Delaney, T. P., Bonasera, B. M., and Beer, S. V. 2003. Harpin-elicited hypersensitive cell death and pathogen resistance requires the NDR1 and EDS1 genes. Physiol. Mol. Plant Pathol. 62:317-326.

27. Peng, J. L., Zhao, J., Pan, X. M., Zhao, J. F., Dong, H. S., and Wang, J. S. 2002. Riboflavin activates growth signal transduction pathway in plants. J. Nanjing Agric. Univ. 25:33-36.

28. Powers, H. J. 2003. Riboflavin (vitamin B-2) and health. Am. J. Clin. Nutr. 77:1352-1360.

29. Rao, M. V., Lee, H-I, Greelman, R. A., Mullet, J. E., and Davis, K. R. 2000. Jasmonic acid signaling modulates ozone-induced hypersensitive cell death. Plant Cell 12:1633-1646.

30. Rensink, W. A., Pilon, M., and Weisbeek, P. 1998. Domains of a transit sequence required for in vivo import in Arabidopsis chloroplasts. Plant Physiol. 118:691-699.

31. Rivlin, R. S. 1975. Riboflavin. Plenum Press, New York.

32. Roje, S. 2007. Vitamin B biosynthesis in plants. Phytochemistry 68: 1904-1921
33. Ryals, J. A., Neuenschwander, U. H., Willits, M. G., Molina, A., Steiner, H. Y., and Hunt, M.D. 1996. Systemic acquired resistance. Plant Cell 8:1809-1819.

34. Sandoval, F. J., and Roje, S. 2005. An FMN hydrolase is fused to a riboflavin kinase homolog in plants. J. Biol. Chem. 280:38337-38345.

35. Sierra, I., and Vidal-Valverde, C. 1999. Kinetics of free and glycosylated B6 vitamins, thiamin and riboflavin during germination of pea seeds. J. Sci. Food Agric. 79:307-310.

36. Stahmann, K. P., Revuelta, J. L., and Seulberger, H. 2000. Three biotechnical processes using Ashbya gossypii, Candida famata, or Bacillus subtilis compete with chemical riboflavin production. Appl. Microbiol. Biotechnol. 53:509-516.

37. Taheri, P., and Höfte, M. 2006. Riboflavin induces resistance in rice against Rhizoctonia sheath diseases by activating signal transduction pathways leading to upregulation of rice cationic peroxidase and formation of lignin as a structural barrier. Commun. Agric. Appl. Biol. Sci. 71:255-258

38. van Loon, L. C., Geraats B. P. J., and Linthorst, H. J. M. 2006. Ethylene as a modulator of disease resistance in plants. Trends Plant Sci. 11:184191.

39. Vorwieger, A., Gryczka, C., Czihal, A., Douchkov, D., Tiedemann, J., Mock, H. P., Jakoby, M., Weisshaar, B., Saalbach, I., and Bäumlein, H. 2007. Iron assimilation and transcription factor controlled synthesis of riboflavin in plants. Planta 226:147-158.

40. Wang, K. L. C., Li, H., and Ecker, J. R. 2002. Ethylene biosynthesis and signaling networks. Plant Cell 14 (Suppl.):S131-S151.

41. Wang, S., and Tzeng, D. D. 1998. Methionine-riboflavin mixtures with surfactants and metal ions reduce powdery mildew infection in strawberry plants. Soil Sci. Soc. Am. J. 123:987-991.

42. Wang, Y., Liu, R., Chen, L., Wang, Y., Liang, Y. C., Wu, X., Li, B., Wu, J., Liang, Y., Wang, X., Zhang, C., Wang, Q., Hong X., and Dong, H. 2009 Nicotiana tabacum TTG1 contributes to ParA1-induced signalling and cell death in leaf trichomes. J. Cell Sci. 15:2673-2685.

43. Wolinsky, I., and Driskell, J. A. D. 1997. Sports Nutrition: Vitamins and Trace Elements. CRC Press. Boca Raton, FL.

44. Xiao, S., Dai, L. Y., Liu, F. Q., Wang, Z. L., Peng, W., and Xie, D. X. 2004. COS1: An Arabidopsis coronatine insensitive1 suppressor essential for regulation of jasmonate-mediated plant defense and senescence. Plant Cell 16:1132-1142.

45. Zhang, H. T., Yan, Z. Q., Hu, X. B., Yang, S. L., and Gong, Y. 2003. Interaction of $\mathrm{C} 17$ or $\mathrm{f} 25$ with ADP-ribose pyrophosphatase NUDT9 detected via yeast two-hybrid method. Acta Biochem. Biophys. Sin. 35:747-751.

46. Zhang, S. J., Yang, X., Sun, M. W., Sun, F., Deng, S., and Dong, H. 2009. Riboflavin-induced priming for pathogen defense in Arabidopsis thaliana. J. Integr. Plant Biol. 51:167-174.

47. Zubay, G. 1998. Biochemistry, 4th ed. WC Brown Publishers, Dubuque, IA. 